\section{A DIAGNOSTIC SIGN OF GELATINOUS CARCINOMA OF THE BREAST}

\section{W. S. HALSTED, M.D. BALTIMORE}

I recall having examined within the past twelve years five cases of colloid carcinoma of the breastcases in which the colloidal portion (or portions) of the new growth was large enough and near enough to the surface to be palpable. In all but one of these there was conveyed to the finger on testing for elasticity a peculiar sensation which in the first instance made me apprehensive lest I had ruptured a possible capsule of the nodule, although there was no apparent alteration in its size or shape.

I find it difficult to describe the tactilè impression. It might be defined as a delicate swish or crush of a jellylike structure under tension, with the suggestion of a delicate bursting.

In no instance have I obtained the sensation twice in the same case, nor has any assistant felt it on making the examination before or after mine. Presumably there is lost to the physical properties of the tumor a something essential to the production of the sign.

In Case 1, a large lobulated colloid carcinoma, the sign was not observed.

In Case 2, the right mamma had been amputated for a carcinoma which in spots was colloidal. A year or two later this patient returned with what seemed to be a like growth of the opposite breast. It was faintly lobulated and in places seemed to be elastic. While I was testing, with moderate force, the resiliency of one of the nodules, the described sensation under the finger was noted. I was alarmed, thinking that I must have ruptured some portion of the tumor, and urged the patient to permit operation at once. She did not consent, and returned to her home in another city. I wrote to her afterward, but was never given the opportunity to determine the, nature of the growth.

The third patient presented herself a year or two later. Nothing was observed at the first examination of her mammary tumor to recall the previous case. But on the operating table, in the course of the examination under ether, the faint but unmistakable "swish" was felt. The carcinoma proved to be of the colloid variety, and there was no macroscopic evidence of damage having been done to the tissues by the examination.

It was perhaps five or six years after this experience that Dr. Finney invited me one day to come to his clinic to examine the breast of a patient under ether on whom he was about to operate. The tumor, about the size of a guinea-egg, was, as I recall it, not unquestionably elastic. Trying to determine this particular point and while I was exercising, perhaps, rather more force than usual, the identical swishing or crushing sensation was reproduced at my finger tips. Instantly the two previous experiences were recalled to mind, and I tentatively predicted colloid carcinoma; and such the tumor proved to be.

The fifth patient, referred by Dr. Branson of Philadelphia, consulted me a few weeks ago. The tumor was unmistakably a carcinoma, hard and infiltrating. . There was a suggestion of elasticity near the surface. The patient was admitted to the Johns Hopkins Hospital, April 12. On the operating table, five days later, in the course of the examination under ether, - he crush or swish, the characteristic (I do not venture to say pathognomonic) sensation was felt over the elastic spot. The diagnosis of colloid carcinoma was made with considerable confidence, and it proved to be correct. The deeper part of the neoplasm was a typical scirrhus; surmounting this was an ovoid nodule, about $3 \mathrm{~cm}$. in diameter, of colloid carcinoma.

In none of the cases was there recognizable any macroscopic evidence of traumatism.

Inasmuch as this sign manifested, I might say obtruded, itself unsought in the four successive cases, it is not possibly a creation of my fancy.

In each instance the unmistakable swish was a surprise. Not once had I in mind the possibility of colloid cancer until the peculiar sensation was felt.

I have not experienced this tactile impression nor have I tested for it in colloid goiter.

I shall be interested to learn if other surgeons have made this observation.

1201 Eutaw Place.

\section{SARCOMATOUS DEGENERATION OF A UTERINE FIBROMA FIVE YEARS AFTER ROENTGEN-RAY TREATMENT FOR PRESSURE AND HEMORRHAGE *}

\author{
GEORGE ERETY SHOEMAKER, M.D. \\ Gynecologist to the Presbyterian Hospital
}

PHILADELPHIA

The subject of the treatment of fibromas of the uterus by non-surgical methods is one of such importance, that all data having a bearing on the subsequent behavior of such growths should be carefully recorded. The time must of necessity be very great which must lapse in any individual case, before the final evidence can be secured as to the subsequent degenerations, for example, after the application of the Roentgen ray or radium. Of peculiar importance is the question whether the sarcomatous or other forms of malignant degeneration are less liable to occur after such treatment, or whether they occur at all.

While no exact percentage can be given, it is certain that sarcomatous degeneration is a definite risk in untreated fibroma of the uterus.

Many series of reports, especially those of aggregates made up from many sources, are almost without statistical value, as for a long time in many clinics, routine examination of all tumors was not made, only those being studied which looked suspicious to the eye.

Winter $^{1}$ in a series of 253 cases examined systematically, found 4.3 per cent. of sarcoma.

Ellice MacDonald, ${ }^{2}$ analyzed seven hundred carefully studied cases and found malignancy complicating in 5 per cent. of all cases, though but 1 per cent. were sarcomatous. Necrotic changes were found in 8 per cent.

Certain writers have argued that after Roentgenray treatment no cases of malignancy have been observed. It is obvious, however, that not until the end of the patient's life, can it be stated that malignant degeneration will not occur. The Roentgen-ray treatment of fibromas has been carried out for but comparatively few years, so that it will be many years

\footnotetext{
* Read before tre College of Physicians of Philadelphia, April 7, 1915.

1. Winter: Ztschr. f. Geburtsh. u. Gynäk., 1906, lvii, 23.
} p. 93 . 